\title{
Getting it right in the mix: Teaching social work practice skills inclusively to diverse student groups
}

\section{Sophie Goldingay}

Deakin University

\begin{abstract}
Social work has traditionally attracted a diverse mix of students with varying levels of academic preparedness and practice skill experience. Current trends in higher education indicate the possibility of further challenges for academic staff in social work as universities seek to both widen participation from university graduates and, at the same time, prioritise practice and academic excellence among students. Drawing on reflective journal entries by the author, this paper examines the challenges that social work academics might face in teaching social work practice skills effectively to the increasingly diverse student cohorts enrolled across Bachelor and Masters of Social Work (Qualifying) degrees. The reflective process adopted in this study explores the gaps between the author's intentions and the reality of the classroom experience. Key observations included language barriers impeding engagement with the material and cultural differences in relating to others and conceptualising practice. These problems were apparent in both the process of delivery (pedagogy) and content (curriculum). The reflective process highlighted the need for further research in order to optimally respond to the diversity in social work education.
\end{abstract}

Keywords: Inclusion, diversity, curriculum development, pedagogies, skills teaching, cultural competency 


\section{Introduction}

Inclusive tertiary education and widening participation are practices gaining momentum across universities in Australia and the United Kingdom (UK) (Chowdry et al., 2010; Richardson, 2010; Stubley \& Woods, 2010). In Australia, these practices serve as solutions to an identified need to successfully educate more of the population and maintain an internationally competitive and skilled workforce (Bradley, 2008). Similarly, in the UK, there is an emphasis on attracting and retaining students who 'have the talent to succeed' (Browne, 2010, p. 2), irrespective of their socio-economic status, age, ethnic background, disability, class and level of academic preparedness (Gordon et al., 2010). This effort to further inclusive practices is accompanied by directives from professional associations and employers of social workers to universities to enhance the status of social work and the value of the qualification by focusing on 'effectiveness and practice' (Dinham, 2006, p. 838).

Directives from professional associations and employers can potentially create some tensions for teachers in the tertiary environment. For example, it has been argued that recruiting students who are not as academically prepared for study in the Australian environment for the sake of widening participation (and receiving government financial incentives) is not reasonable if teachers do not correspondingly adjust their teaching to make the material more accessible and hence more inclusive (McKinnis as cited in Nakata et al., 2008; Richardson, 2010). Others argue that adjusting teaching practices to suit diverse student groups who are less used to Australian pedagogy might result in lowering standards (for example, Trounson, 2010), thus diminishing the overall value of the social work degree. In this view, changing the pedagogy and curriculum to be more inclusive of diverse student groups may be seen to disadvantage those who are able to work effectively within the current framework, as it could be perceived as 'dumbing down' the material and compromising the value of the degree.

To harmonise these conflicting viewpoints, it is necessary to investigate how the process of inclusion is enacted and experienced in a classroom setting during professional social work training (Gordon et al., 2010). This paper uses written reflections by the author as a framework to discuss challenges and opportunities for meaningful learning that arose during three trimesters of social work practice skills. In particular, the paper problematises my own approaches to teaching practice skills to students who are Culturally and Linguistically Diverse (CALD). Not only did I find it challenging to be truly inclusive of these students in my teaching practices, but important cross-cultural learning opportunities may have been missed as well.

I conclude that one reason for these missed opportunities and difficulties in practising social inclusion is the lack of frameworks for highlighting shared experiences across diversity. I also argue that there needs to be a framework that can acknowledge and value the diverse epistemologies (ways of thinking, communicating and creating knowledge) students bring to the classroom, irrespective of their background. I pose some questions for myself and others like me who are committed to equity and social inclusion in higher education. It should be noted that this paper is not intended to form 
an evaluation of the outcomes of social work education since this topic has been explored elsewhere (for example, Carpenter, 2011). Rather, this paper explores the equity issues in relation to teaching social work practice skills to CALD students in Australia.

\section{Setting/course description}

The development of social work practice skills is a key component of learning to be a professional social worker. Practice skills have been taught using role play and experiential learning techniques in Australia for many years and are an accepted way to teach social work practice skills (for example, Maidment, 2009; Trevithick, 2005). During class, students are supported to learn constructive ways of giving and receiving feedback, and then provided with case studies of clients who face complex social problems across a range of settings such as health, mental health and criminal justice. They are then expected to use their knowledge of the practice skills and theories during a role play activity, with one student playing the client and another student playing a social worker, while one or more students observe. After performing the role play, students receive constructive feedback (but are not formally assessed) within small groups of their fellow students with support from teaching staff.

The pedagogy underpinning the teaching of social work practice skills is different from that of other courses in the degree owing due to the performance expectations from the learning outcomes. Rather than the focus being on recall of espoused theories, students are required to demonstrate that they can perform 'theory in use' (Biggs, 1996, p. 347). Skills required to be performed include active listening, appropriate and purposeful questioning, eye contact and body language, together with the knowledge of how to put key theoretical frameworks into practice such as the strengths-based theory, the systems theory, crisis intervention and anti-oppressive practice (Maidment, 2009).

\section{Current understandings of teaching cross-cultural social work practice skills}

The Australian Association of Social Workers (AASW) specifies that graduate social workers must demonstrate beginning skills in working with all clients in culturally sensitive ways (AASW, 2010). 'Culturally sensitive' in this sense refers to the ability to reflect on one's own cultural location, both personally and within the organisation that practice takes place (AASW, 2010; Furlong \& Wight, 2011), and to have an ongoing interest in developing knowledge of how to work with cultures that are different to their own (AASW, 2010). Thus, all students must have this beginning level of cultural competence in order to graduate from an accredited social work course and thus be eligible to become members of the AASW.

To this end, during practice skills teaching sessions, students are encouraged to reflect on their own cultural location and identify the impact of the dominant (EuroWestern) culture on expectations of 'competent' practice in many agency settings. Such cultural practices within 'white' culture (Walter, Taylor \& Habibis, 2011) may include a 
focus on concise, direct communication and direct eye contact, and the need to keep the conversation 'moving' and 'focused'. Such practices may conflict with cultures that value the practice of storytelling and metaphor (Lynn, 2001). Further, in some cultures, the ability to sit, listen and respect silence is important (Briggs, 2009). For others, some forms of eye contact, body language and questioning styles common in Western culture and practice settings might be seen as inappropriate or disrespectful (Cooper \& Rigney, 2009).

Thus, mastery of the material entails the complex process of integrating theory, process and interpersonal skills, and a consideration of one's cultural and social location and its impact on what are considered social work practice skills. In addition to mastery of the skills, experiential learning techniques are intended to help students gain confidence in their future roles as professional social workers. In keeping with Napan (2002), I intended the social work practice skill classroom to be a laboratory for effective social practice'(p. 126) at all times, whereby students have learning experiences that they can then apply to real practice settings both in practicum and in future paid work.

A positive learning climate has been cited as a key component for learning this type of material (for example, Greenhalgh et al., 2006; Maroulis \& Gomez, 2008; Nakata et al., 2008). The challenge within the current pedagogy and curricula, with the diverse range of students participating, is maintaining respect, connectedness and a positive learning climate in the classroom while implementing demanding role play and small group discussion activities. It is this ongoing challenge that prompted my use of critical reflection (Fook, 2002; Fook \& Gardner, 2007) in order to try and unpack my own assumptions that might hinder effective teaching practice.

\section{Theory in relation to use of critical reflection to improve practice}

I began a process of journaling with the view of engaging in critical reflection (Fook, 2002). If a classroom event puzzled me or went particularly well, I wrote story-like narratives of my thoughts and feelings in relation to the events. I worked to interrogate my assumptions and consider alternative perspectives to my own. My interest in critical postmodern approaches to teaching (for example, Morley, 2008), made me particularly concerned to uncover if language or actions I used in the classroom perpetuated social inequities or exclusion among students. I did not use this process to discover the 'truth' or 'what actually happened' (Haug, 2008, p. 540; Jasper, 2005). Rather, my intention was to become more mindful during my teaching practice (Shulman, 2000) and to transcend and engage with difference (Osmond \& Darlington, 2005). I hoped that this process would help me develop and refine my skills further in teaching professional practice skills.

\section{My own positioning}

One of the frameworks that guides my teaching, research and social work practice, which arises from my own background of working in New Zealand, is to take a 
decolonising (Tuhiwai-Smith, 1999) stance. This involves me taking responsibility for my own colonialism. It means working to be mindful of how I might inadvertently privilege Euro-western values, beliefs and practices at the expense of the values, beliefs and practices of non-dominant cultures. In saying this, while I appear white, other close members of my family appear 'coloured' because of our African and South American descent. I am aware of, and have strong feelings about, my family members' experiences of racial prejudice, such being called 'nigger' and 'golliwog' at school. Being female, in my forties, university educated, a social work practitioner for two decades, and a mother of school-aged children also influences my positioning in relation to social inclusion in my classroom teaching in various ways, as will be seen from my analysis of my reflections.

\section{Literature in relation to CALD students in social work higher education contexts}

Literature in Australia has attested to the challenges experienced by international students, whether they enter universities through Special Entry Access Schemes (SEAS) (for example, Hosken, 2010; Jones, 2006) or if they are full-fee paying students from countries such as Hong Kong, India, Malaysia or Thailand (Taylor, Craft, Murray \& Rowley, 2000). These challenges include problems with social behaviour and conventions, language difficulties, and the pervasiveness of the belief systems of the dominant culture, which have the effect of silencing their articulation of their needs or cultural beliefs (Irizarry \& Marlowe, 2010; Taylor et al., 2000). Other important issues raised in the literature include whether our role is to prepare students for social work in Australia or to prepare them to practice in their own country or culture of origin (Taylor et al., 2000).

Of particular relevance to this paper is the difficulties faced by international students in participating in experiential and small group work (Samuelowicz as cited in Irizarry \& Marlowe, 2010; Taylor et al., 2000), which forms the core pedagogical tool for teaching and learning social work practice skills. This literature is in contrast to other scholarship that suggests that strategies that employ hands-on small group work are the most effective way to engage groups traditionally under-represented in higher education settings. Small group and experiential teaching methods are promoted as the ideal by these writers because it is believed that it will invoke a climate of respect and connectedness-key contributors to effective learning (for example, Greenhalgh et al., 2006; Maroulis \& Gomez, 2008; Nakata et al., 2008).

Gillingham (2008) also supports the use of experiential role play in teaching social work practice skills, as he draws attention to the potential for 'transformative learning', which occurs when students' points of view and habits of mind are challenged as a result of their involvement in role plays and group discussions. 
According to this view, a degree of discomfort is required to motivate learning (Fook \& Gardner, 2007). It is within these contradictory positions about the efficacy of small group work for diverse groups that my exploration about how I teach practice skills to CALD students occurs.

To situate the context for the current study, I will draw on data from a recent project in which I participated that explored the first year experience for undergraduate social work students and gathered specific data around student demographics in first year intakes from Deakin. From a sample that constituted 33 per cent of the total student population of 150, 16 per cent were born overseas, with four per cent stating that English is not their primary language and six per cent stating that English was not their primary language spoken at home (Goldingay et al., forthcoming). While these are low numbers, I anticipate this to grow due to the government's widening participation agenda and Deakin's commitment and track record of a high proportion of international student enrolments (Australian Education International, 2011).

\section{Method}

I wrote my journal entries regularly after lecture delivery of both Masters and undergraduate practice skills units over the two-year period between 2010 and 2011. The year level and year will not be identified in the reflection extracts that follow in order to maintain the anonymity of students in the classes. Permission was obtained from the Human Research Ethics Committee for waiver of consent from those observed because the data is not identifiable and I am no longer able to identify to which students the reflections refer.

At the end of the reflection period, a thematic analysis (Taylor \& Ussher, 2001) of my reflective journal was conducted in order to identify patterns and themes that were relevant to my inquiry of teaching social work practice skills in an inclusive manner to diverse student groups. The themes of comfort, relevancy, accessibility and assimilation emerged from my thematic analysis of my reflective journal. All themes contained an element of tension and contradiction, as will be demonstrated by the extracts.

\section{Findings}

\section{Comfort with discomfort}

All students appeared to experience discomfort at the prospect of engaging in a new form of learning, irrespective of their background, and I worked hard to put them at ease. My own positioning in relation to this discomfort is contradictory due to a strong desire to protect students and ensure they have positive experiences. On reflection, I think this motive may be present due to a complex combination of my own experiences of social work training and feelings about vulnerability, my age, gender, ethnic background, and status as a mother. 
In each trimester, by the third lecture, most students were generally engaging fully with the role plays and having positive learning experiences. However, CALD students stood out as not fully engaging and as a result of their discomfort, I felt at a loss of how to proceed. The following extract demonstrates how the contradiction of wanting my students to learn and grow, yet wanting to protect them, stymied my ability to address some of the difficulties in class:

I listen to the role play [consisting of two CALD students] and realise that neither student has the same understanding of the exercise as the Western students do. No wonder the other students don't want to give feedback to them. After the class, I agonise about how to support all the CALD students and the Western students trying to work with them.

There are a number of assumptions embedded in the statement 'no wonder the other students don't want to give feedback to them' of which I was not aware at the time of writing the journal. One is that I assumed that the Western students feel as protective towards the CALD students as I do, and do not want to 'correct' them for fear of appearing racist or imperialist. Another assumption is that students experience a level of frustration in having to work with peers who are not 'up with the play'. I assumed that the students who are comfortable with the material want to progress and learn it without impediment. However, what is left out of this picture is the knowledge that CALD students bring into the role play, and the different perspective they may have of the particular client scenario. The potential for such perspectives to enrich all students' (and my) overall practice competence is overlooked. In addition, there is no space or framework to bring these knowledge bases and epistemologies to the fore, and at the time of writing, I struggled to see a way to include CALD students in the learning without singling them out, embarrassing them, or making them feel even more uncomfortable than they already did.

\section{Comfort with difference itself}

I was also troubled by the ways that local or 'home' students appeared to actively avoid working with CALD students when they could. If they were in a position in which they were not able to avoid working with CALD students, they would not participate as actively and would look uncomfortable. To me, this situation did not appear to be a positive learning environment and it certainly was not socially inclusive. A key problem appeared to be difficulties in understanding each other due to language barriers. Moving beyond the language issue, a complex interplay of different cultural practices in relation to defining what constitutes appropriate behaviour and practice seemed to create a swampy ground where both students and I struggled to find firm footing.

My concern about the relationships between local and CALD students led me to investigate how other Australian scholars had approached the issue of working with international students. I found Betty Leask's (2009) study that considered how to 
improve interactions between home and international students in South Australia. Leask draws attention to the potential that widening student diversity has 'for successful crosscultural engagement' (Leask, 2009, p. 205). While this fits well with my intention of assisting all students to develop their cross-cultural literacy, it did not help me move beyond the cultural and language differences that seemed major block to cross-cultural engagement and social inclusion in my class. However, my quandary was validated by reading Leask because she writes that she too had 'difficulties getting international and domestic students to work collaboratively together' (2009, p. 207).

\section{Accessibility}

Another theme that arose within my reflections was my concern about how some students found the experiential learning pedagogy of teaching practice skills itself to be inaccessible. Literature has attested to the challenge international students might face working in small groups due to an expectation of teaching and learning being more hierarchical with only the lecturer having knowledge (Taylor et al.,2000). In addition to this, I began to wonder if the practice of students giving and receiving feedback to and from each other was completely foreign, or even offensive or inappropriate, to those who had not been brought up in a Western educational system. Maidment (2009) also observed that it is also important to acknowledge that not all students will necessarily have been educated in a Western system. As such the capacity of some students to actively experiment and demonstrate skills in peer groups could be challenged' (p. 19).

The following entry was written after a number of classes in which Western students appeared to be very uncomfortable while working with CALD students in one of the trimesters. As one of the objectives of role play is to improve student confidence in practice, I decided to address the discomfort I had observed in class and identify some solutions. The following are my reflections on this process:

I ask how everyone is feeling about role plays. The student who looked the most uncomfortable last week tells me that she would rather I gave the feedback after small group role play. Some students nod in agreement. The complexity and consequences of students providing feedback about role play to someone who appears only to be 'just getting by' due to cultural and language barriers is deeply concerning me.

This reflection highlights one of the challenges of the experiential learning environment in which not everyone is at the same starting point. Failure to reach a level of skill and confidence in practice is humiliating, especially if exposed by a peer. Language and cultural barriers appear to intensify this problem since the process of small group work and giving and receiving feedback seemed so far removed from what the CALD students were expecting or were used to.

The difficulties facing CALD students in experiential settings within social work degrees is now particularly salient given the growing numbers of SEAS and international 
students accessing Australian university, as discussed earlier. Nevertheless, it is important to consider some solutions to it since, as stated by the International Association of Universities, 'access without a reasonable chance of success is an empty phrase' (2008, p. 1). The following journal extract was written after a number of sessions in which CALD students did not participate as actively in the experiential role play activities, which caused me some concern:

I notice some students now move into the role plays relatively easily, whilst others are still clearly very nervous. One of the CALD students seems to get her textbook out and bury herself in it when we are doing a role play.

Again, I was at a loss as to how to encourage this student and other CALD students to participate as fully in the experiential role play sessions as the other students, which led me to further examine whether indeed I should be making them do it or if I should somehow find another method of teaching and learning social work practice skills that would suit them better. I could not see a way past the fact that they would be assessed not only on their understanding of theoretical material but also on their ability to participate in conversational situations in which a significant amount of verbal and nonverbal information is exchanged. As with other cultures, many social protocols familiar to Western students are tacit as opposed to overt. This brings me to the next two themes identified in my journal: assimilation and relevancy of content.

\section{Assimilation}

Related to the issue of accessibility is the question of assimilation. When students attend university, there is an expectation that they will adapt to and adopt the culture and practices of the institution-a process that could be described as assimilation. Analysis of my journal led me to see that the contradictions and tensions in my feelings about students' assimilation into Australian culture and university processes were a recurring theme. For me, a key tension occurred between supporting students to learn using Western teaching methods and skills on the one hand, and supporting and acknowledging teaching practices and conventions that may not be of Western origin on the other.

I am very committed to small group and experiential pedagogy as it fits with my Rogerian constructivist stance on teaching and learning that 'we cannot teach a person but can only facilitate their learning' (Stacey, 1998, p. 1). For me, this means that teaching is a two-way conversation in which students discuss their own ideas and we develop shared meanings together. The idea of teaching students in a hierarchical lecture-like manner (as discussed by Taylor et al., 2000) is definitely not my preference for teaching this material, nor do I believe it enables students to achieve the performance of theory-in-use that is required for this subject: 
I work hard at having both small group and large group discussions to enable all students, no matter how confident or inexperienced, to hear themselves talk. To answer some searching questions around how we might work with clients

I can see that a subtext within this extract is that I expect students to learn that 'this is the way we do things here', with a belief that the small groups will assist them to participate in other aspects of their working life in Australia, including the practicum part of their training. I can also see, from analysing this reflection, that what I intend to do (that is, engage students in their learning) is not in keeping with what actually happens for some students in practice. This suggests a need for much closer inquiry and future research to understand students' perspectives on this.

\section{Relevancy}

Another theme that emerged as a result of my analysis was that of the relevancy of material. My journal indicates that during classes, some skills that were taught as part of the curriculum seemed particularly unsuitable or irrelevant for some students. For example, when teaching the 'constructive challenge' part of the course, I observed that the CALD students did not understand the concepts discussed and they failed to do as instructed, in contrast to the local students who knew exactly what I was asking. I wondered if the individualised nature of the techniques being taught, which were derived from Western theoretical traditions, would ever be relevant to a practice situation for Indigenous Australians or in an African or Asian country. In a subsequent week, I wrote the following questions in my reflective journal after another class during which the expressions on CALD students' faces appeared to me to demonstrate bafflement when I discussed various processes of working with families according to our set text:

How can I, as unit chair, assess cross-cultural work and upon what basis? How should I teach a set curricula of practice skills when what constitutes skill is culturally determined?

These questions led me to a further avenue of inquiry, moving beyond pedagogy and towards curriculum that is relevant in today's global context. The goal of the practice skills units is to equip students with the skills required in their practicum, and ultimately, in the workforce. In keeping with the literature (for example, Taylor et al., 2000), I experienced uncertainty as to whether I should be preparing students to practice in the Australian context or whether I should be equipping them to work with clients in the students' home countries or communities.

The process of reflection and wider consultation with colleagues led me to realise that such tensions around assimilation, comfort and relevancy are as much present in practice settings as they are in the classroom and that what was happening in my class in many ways mimicked the real world of practice. Nevertheless, I still felt stymied. How could I proceed to take advantage of these cross-cultural opportunities for learning in 
ways that would not come across as exploitative, patronising or be embarrassing to students? How could I develop pedagogy that was inclusive of all students? What processes should be used to incorporate non-Western knowledge and cultural practices into the curriculum and pedagogy? Which knowledges and whose interpretation of the knowledges would be used? How could these changes be made while meeting the industry, academic and professional association (for example, AASW) expectations of the degree?

\section{Discussion}

I found in my exploration of the literature that I was not the only tertiary teacher who was investigating these concerns. Nakata and colleagues (2008), in their discussion of the Indigenous Australians' experience of tertiary education, have also observed the tension of 'institutional accommodation of diversity versus individual indigenous accommodation of academic practices' (p. 142). They identify that legitimising the Indigenous student's knowledge as assets to the classroom could be one potential way forward in terms of how universities should respond to Indigenous Australian students. They note that knowing how to equip students in the endeavour of not only mastering course content and pedagogy but contributing to its development is an 'under-explored area of research' (Nakata et al., 2008, p. 142).

The potential benefit that social work courses can derive from such research is significant because negotiating complex situations that include language and cultural differences forms a core part of social work. The opportunity to experience diversity in a 'safe' classroom situation prior to placement and employment can provide social work students with valuable skills. The opportunity to develop curricula and pedagogy that is inclusive of non-Western students is also an opportunity for development of Westerneducated teachers and students alike.

Further, there is growing awareness of the Euro-centeredness of social work practice and its consequential lack of relevance for non-Western cultures (Mwansa, 2010). Social work as it is taught and practiced today originated in Europe; from European history and a European value base. It is dominated by notions of independence and empowerment and a philosophy that centres on the individual (Mwansa, 2010), which may not be relevant for all communities of the world. Thus, teaching these notions as core to social work practice is likely to impede efforts to develop an inclusive curriculum.

Research into ways of including non-Western 'ways of knowing' into the curricula and pedagogy to improve the relevance of the material for the settings in which social work students will eventually work will invariably improve the richness and value of training for all social workers and not just those whose knowledge bases are acknowledged. However, there are a number of problems with this concept. The first is that the diverse student population is not static; it changes from trimester to trimester. Therefore, the issue is not restricted to being competent in a static array of cultures because this would lead to fixed generalisations of limited use (Ortiz \& Jani, 2010). The 
second problem concerns language. As identified in this paper, the CALD students in my class appeared considerably disadvantaged owing to their language barriers. Attempting to master a socially complex skill such as social work practice and obtaining good grades within the current pedagogy without mastering the English language seemed to be an impossible task. Future research should consider this practical barrier and identify solutions that will eliminate the obvious disadvantage faced by such students in a culturally appropriate way.

A third problem is the potential exploitation that non-Western students might experience as a result of being called upon to present perspectives that are different to the dominant Western knowledge bases. Universities have been identified as 'vestiges of White privilege' (Ortiz \& Jani, 2010, p. 180). Therefore, it is necessary to consider how teachers will contest the dominance of privileged viewpoints and make space for other more suppressed knowledge systems (Pease, 2010) without continually relying on students to advocate these.

\section{Conclusion: Where to from here?}

Thus, a number of questions remain unresolved as I write this paper. I identified tensions within the themes of accessibility and comfort, assimilation and relevancy during analysis of my reflective journal. Within the accessibility theme, issues related to language barriers and the small group experiential pedagogy that had hitherto been 'the way' to teach social work practice skills. Within the theme of 'comfort', tensions arose for me with respect to a desire to give students a positive learning experience, but at the same time allow for a certain level of discomfort in order to engage in transformative learning were also apparent in my reflections. Putting the theory of cross-cultural work into practice even in a classroom setting was challenging for both my students and I, where the awkwardness due to difference in cultural practices and language barriers stymied connection and understanding in the classroom at times.

Assimilation and relevancy were other themes that emerged from my reflection and contradictions about these issues still remain. How much should I expect students to adjust to my teaching methods because they fit with my beliefs about teaching and learning? How can I make content relevant to all? I still have questions in relation to the degree to which I can prepare students for practice in their home country or even their ethnic community here in Australia. Reflections on my teaching practice suggest it is not enough for me to only tell students that cultural location affects practice. It is also necessary to be willing to introduce practice situations that call on alternative paradigms than those that emphasise empowerment, independence and individualism. This is likely to feel uncomfortable for a significant number of students and teachers alike and some teachers may feel at a loss as to how to develop and enact such situations and also how to assess them in summative assignments. There is also the issue of which alternative paradigm to draw upon.

Nevertheless, irrespective of which knowledge based is introduced, and which pedagogy is utilised, the experience of having to accommodate an alternate worldview 
and learning practices may assist students in dominant and privileged groups to understand what it is like for those who negotiate biculturalism or even multiculturalism every day while living in Australia. Through shared experiences such as this, I contend that respect and connectedness may follow and international students may feel more included in the learning endeavour. Further research, which includes student perspectives on pedagogy and curriculum in practice skills, is required to work towards more effective social inclusion teaching practices for CALD students.

\section{References}

Australian Association of Social Workers (2010). Australian social work education and accreditation standards. Retrieved 28 February 2012, from http://www.aasw.asn.au/document/item/100Australian social work.

Australian Education International (2011). Research snapshot: Onshore higher education international students as a proportion of all onshore students by university, 2010. Retrieved 21 May 2012, from https://www.aei.gov.au/research/Research-

Snapshots/Documents/International\%20students\%20in\%20Australian\%20unis\% 202010.pdf.

Biggs, J. (1996). Enhancing teaching through constructive alignment. Higher Education, 32(3), 347-364.

Bradley, D. (2008). Review of Australian higher education. Retrieved 27 February 2012 ,from

http://www.deewr.gov.au/HigherEducation/Review/Documents/PDF/Higher\%20E ducation\%20Review one\%20document 02.pdf.

Briggs, L. (2009). Collaborative assessment from a cross-cultural perspective. In J. Maidment \& R. Egan (Eds). Practice skills in social work and welfare: More than just common sense (pp. 170-180). Sydney, NSW: Allen \& Unwin.

Browne, J. (2010). An independent review of higher education funding and student finance. $\quad 15$ Retrieved December 2010, from http://hereview.independent.gov.uk/hereview/report/.

Carpenter, J. (2011). Evaluating social work education: A review of outcomes, measures, research designs and practicalities. Social Work Education, 30(2), $122-140$.

Chowdry, H., Crawford, C., Dearden, L., Goodman, A. \& Vignoles, A. (2010). Widening participation in higher education: Analysis using linked administrative data. Retrieved 9 December 2011, from http://www.ifs.org.uk/wps/wp1004.pdf.

Cooper, L. \& Rigney, D. (2009). Preparing for practice. In J. Maidment \& R. Egan (Eds). Practice skills in social work and welfare: More than just common sense (pp. 6277). Sydney, NSW: Allen \& Unwin.

Department of Education Employment and Workplace Relations (2009). Transforming Australia's higher education system. Retrieved 25 March 2011, from http://www.deewr.gov.au/HigherEducation/Documents/PDF/Additional\%20Report \%20-\%20Transforming\%20Aus\%20Higher\%20ED webaw.pdf.

Dinham, A. (2006). A review of practice of teaching and learning of communication skills in social work education in England. Social Work Education, 25(8), 838-850.

Fook, J. (2002). Social work: Critical theory and practice. London, UK: Sage.

Fook, J. \& Gardner, F. (2007). Practising critical reflection: A resource handbook. Berkshire, UK: McGraw Hill Open University Press. 
Furlong, M. \& Wight, J. (2011) Promoting 'critical awareness' and critiquing 'cultural competence': Towards Disrupting Received Professional Knowledges. Australian Social Work, 61(1), 38-54.

Gillingham, P. (2008). Designing, implementing and evaluating a social work practice skills course: a case example. Social Work Education, 27(5), 474-488.

Goldingay, S., Lamaro, G., Hitch, D., Hosken, N., Macfarlane, S., Farrugia., D., Nihill, C., \& Ryan, J. (Forthcoming). Perceptions of academic skills from first year social work students. The International Journal of the First Year in Higher Education

Gordon, J., Dumbleton, S. \& Miller, C. (2010). We thought we would be the duncesFrom a vocational qualification to a social work degree: An example of widening participation in social work education. Widening Participation and Lifelong Learning, 12, 169-184.

Greenhalgh, T., Russell, J., Dunkley, L., Boynton, P., Lefford, F. \& Chopra, N. (2006). We were treated like adults-Development of a pre-medicine summer school for 16 year olds from deprived socioeconomic backgrounds: Action research study. British Medical Journal, 332(7544), 762-766B.

Haug, F. (2008). Memory work. Australian Feminist Studies, 23(58), 537-541.

Hosken, N. (2010). Social work and welfare education without discrimination: Are we there yet? Practice Reflexions, 5(1), 3-16.

International Association of Universities (2008). Equitable access, success and quality in higher education: A policy statement by the International Association of Universities. Adopted by IAU $13^{\text {th }}$ General Conference, July, in Utrecht. Retrieved 17 February 2011, from http://www.iauaiu.net./access he/access statement.html.

Irizarry, C. \& Marlowe, J. (2010). Beyond mere presence-making diversity work. Social Work Education: The International Journal, 29(1), 96-107.

Jasper, M. (2005).Using reflective writing within research. Journal of Research in Nursing, 10(3), 247-260.

Jones, K. (2006). Valuing diversity and widening participation: The experiences of access to social work students in further and higher education. Social Work Education: The International Journal, 25(5), 485-500.

Leask, B. (2009). Using formal and informal curricula to improve interactions between home and international students. Journal of Studies in International Education, 13(2), 205-221.

Lynn, R. (2001). Learning from a 'Murri Way'. British Journal of Social Work, 31, 903916.

Maidment, J. (2009). Skill-based learning. In J. Maidment \& R. Egan (Eds). Practice skills in social work and welfare: More than just common sense (pp.18-34). Sydney, NSW: Allen \& Unwin.

Maroulis, S. \& Gomez, L.M. (2008). Does 'connectedness' matter? Evidence from a social network analysis within a small-school reform. Teachers' College Record, 110(9), 1901-1929.

Mwansa, L-K. (2010). Social work education in Africa: Whence and whither? Social Work Education, 1-13.

Morley, C. (2007). Teaching critical practice: resisting structural domination through critical reflection. Social Work Education, 27 (4), 407-421.

Nakata, M., Nakata, V. \& Chin, M. (2008). Approaches to the academic preparation and support of Australian Indigenous students for tertiary studies. Journal of Indigenous Education, 37,137-145.

Napan, K. (2002). Being, loving and contributing. In M. Nash \& B. Stewart (Eds). Spirituality and social care: Contributing to personal and community well-being (pp. 129-150). Jessica Kingsley Publishers. 
Osmond, J., \& Darlington, Y. (2005). Reflective analysis: Techniques for facilitating reflection. Australian Social Work, 58(1), 3-14.

Ortiz, L. \& Jani, J. (2010). Critical race theory: A transformational model for teaching diversity. Journal of Social Work Education, 46(2), 175-193.

Pease, B. (2010). Undoing privilege: Unearned advantage in a divided world. London, UK: Zed Books.

Richardson, J. (2010). Widening participation without widening attainment: The case of ethnic minority students. Psychology Teaching Review, 16(1), 37-45.

Shulman, L.S. (2000). Inventing the future. In P. Hutchings (Ed.), Opening lines: Approaches to the scholarship of teaching and learning. Menlo Park, CA: The Carnegie Foundation for the Advancement of Teaching.

Stacey, E. (1998). Study of the enhancement of learning through group interaction by computer mediated communication. Unpublished doctoral thesis, Monash University.

Stubley, R. \& Woods, N. (2010). Talking about writing in higher education. Paper presented to Where is the Wisdom We Have Lost in Knowledge? Exploring Meaning, Identities and Transformation in Higher Education conference, New South Wales, 14-16 December, Retrieved 28 February 2012, from http://www.srhe.ac.uk/conference2010/abstracts/0052.pdf.

Taylor, S., Craft, C., Murray, D. \& Rowley, D. (2000). International students in Bachelor of Social Work programs across Australia: A case for special educational consideration? Australian Social Work, 53(2), 29-36.

Taylor, G. W. \& Ussher, J.M. (2001). Making sense of S\&M: A discourse analytic account. Sexualities, 4(3), 293-314.

Trevithick, P. (2005). Social work skills: A practice handbook. Berkshire, UK: Open University Press.

Trounson, A. (2010). No student ought to be left behind. The Australian. Retrieved 31 March 2011, from http://www.theaustralian.com.au/higher-education/no-studentought-to-be-left-behind/story-e6frgcjx-1225967194805.

Tuhiwai-Smith, L. (1999). Decolonizing methodologies: Research and indigenous people. Dunedin, Aotearoa NZ: University of Otago Press.

Walter, M., Taylor, S. \& Habibis, D. (2011). How white is social work in Australia? Australian Social Work, 64(1), 6-19.

\section{Biographical Notes}

Sophie Goldingay is a lecturer in the School of Health and Social Development at Deakin University, and is currently Bachelor of Social Work Honours Coordinator. Her research interests include qualitative research with institutionalised populations such as prisoners and people with psychiatric disabilities. She also is involved in research with young people with learning disabilities, and Higher Education students, with a view of furthering the agenda of equity and social inclusion in Higher Education. She led a team of researchers at Deakin to create a Multidimensional Framework for Embedded Academic Skill Development which has led to significant developments across the Faculty of Health, including a Pathways project with the local TAFE in Geelong. The project team have recently received an award for Excellence in Teaching and were 
Journal of Social Inclusion 3(1)2012

nominated for the 2012 Vice Chancellor's award for Excellent Contribution to Equity and Access. 